\title{
MALARIA AND HUMAN IMMUNODEFICIENCY VIRUS (HIV) IN REPUBLIC OF SOUTH SUDAN: A MINI-OVERVIEW By
} AHMAD MEGAHED A. SALEH ${ }^{1}$, MOSTAFA M. ELNAKIB ${ }^{1}$, DENG MAYOM
AROP MALEK ${ }^{2}$ and TOSSON A. MORSY ${ }^{3}$ Military Medical Academy, Cairo11291 ${ }^{1}$, South Sudan People's Defense Forces $(\text { SSPDF })^{2}$ and Faculty of Medicine, Ain Shams University, Cairo $11566^{3}$, Egypt Abstract

South Sudan is the $42^{\text {nd }}$-most densely populated African country $\left(19.2\right.$ inhabitants $\left./ \mathrm{km}^{2}\right)$. The top 10 African countries by population density are: Mayotte (France), Mauritius, Rwanda, Burundi, Comoros, Réunion (France), Seychelles, Nigeria, São Tomé and Príncipe, Gambia, Uganda, Malawi. South Sudan has the 36th-largest legislature in the world by number of members (382 totals). The top 10 legislatures by number of members are: China, United Kingdom, Italy, France, India, European Union, Germany, Japan, Indonesia, Korea, and North. South Sudan is the $76^{\text {th }}$-largest country in the world by population $(12,230,730$, based on estimates published by the United Nations). The top 10 countries by population (United Nations) are: World, China, India, United States, Indonesia, Brazil, Pakistan, Nigeria, Bangladesh, Russia, and Mexico. This is a mini-view to raise awareness about malaria and HIV.

Key words: Republic of South Sudan, Malaria, Anopheles, HIV, Mini-overview.

\section{Introduction}

The Republic of South Sudan gained independence and was recognized as the 193rd United Nations member state on 9 July 2011. The Republic of South Sudan (RSS) is among the countries in the sub-Saharan Africa that are most severely affected by malaria and is currently experiencing an unprecedented outbreak of malaria. Medicines sans Frontiers (MSF) have reported that, in the year 2015, the malaria outbreaks in South Sudan were considered to be the most hazardous in the region (Nguyen, 2016).

\section{Review and Discussion}

The country is facing a number of tremendous challenges, the most notable being the limitation of human and financial resources due to the ongoing war and civilian instability. Nonetheless, the Government Agencies of South Sudan, \& many Non-Governmental Organizations (NGOs) have committed to reducing this ongoing outbreak of malaria. School-aged children and adolescents in the developing world are increasingly recognized as a high-burden demographic for nutritional deprivation and infectious disease, with adverse consequences for their developmental trajectory into adulthood. Beyond the preschool years, during which malnutrition and infectious diseases are the principal determinants of child mortality, school-aged children and youth are also at the risk of the poor health, cognition and educational achievement as a result of under-nutrition and infection. Schools also represent a platform for public health surveillance for the community at large, as well as a convenient and cost-effective platform to deliver health interventions, such as anti-malarial, anthelmintic and micronutrients (Best et al, 2010).

A mutually amplifying relationship between malaria, a leading cause of hospitalization and death in sub-Saharan Africa, and malnutrition has been documented (Lewnard et al, 2014). However, this interaction between malnutrition and malaria is complex and varies depending on the definitions and indicators used for malnutrition measurements (Deribew et al, 2010) More specifically, the literature has supported that stunting (low height-for-age), indication of chronic malnutrition, may increase the risk of malaria (Deen et al, 2002). Whereas wasting (low weight-for-height), the indicator of acute malnutrition, appears to be associated with a decreased risk of malaria (Fillol et al, 2009). Also, a well-documented interaction is that re-feeding of famine victims increases clinical manifestations of malaria, with improved host immunity and/or nutrient re- 
plenish ment that promoted parasite growth (Murray et al, 1976).

Pasquale et al. (2013) mentioned that South Sudan has borne the brunt of years of chronic warfare and probably has the highest malaria burden in sub-Saharan Africa. But, effective malaria control in post-conflict settings was hampered by a multiplicity of challenges. They added that South Sudan was strived to make progress in implementing WHO recommended malaria control interventions as set out in the 2006-2013 National Malaria Strategic Plan. The country has faced enormous programmatic constraints including infrastructure, human and financial resource and a weak health system compounded by an increasing number of refugees, returnees and internally displaced people. The findings present a platform on which to tailor an evidence-based 2014-2018 national malaria strategic plan for the country and a unique opportunity for providing a model for countries in a post-conflict situation. They concluded that the prospects for effective malaria control and elimination are huge in the South Sudan. Nevertheless, the strengthened coordination, infrastructure and human resource capacity, monitoring and evaluation are required.

Charchuk et al. (2015) reported that in Republic of South Sudan now faces poverty, a lack of health care infrastructure, a high burden of infectious diseases and widespread food insecurity. They screened 109 school-aged children and youth for nutritional status and malaria antigenaemia in Akuak Rak, and found underweight (77/109 $=73 \%)$ and prevalent malaria (44/109= $40 \%$ ), but without significant association between malnutrition and malaria. They concluded that. The implementation of nutrition and malaria screening combined with the evidence-based interventions in schools could help target this high burden vulnerable group. These rare data of underweight and malaria among school children in warravaged South Sudan call for implementation of known inexpensive and evidence- based interventions in this high-burden vulnerable group.

Ortu et al. (2017) stated that South Sudan was rolled out as a neglected tropical disease programme, which envisaged the deworming campaigns in states endemic for soil transmitted helminthes infections and schistosomiasis. They reported that Central Equatorial implemented the first helminthes infections and schistosomiasis treatment campaign, gave a satisfactory program coverage (>90\%). Setting up drug distribution sites and engaging the Boma Health Initiative are recommended approaches for future campaigns. Plasmodium species infecting man are $P$. falciparum, $P$. vivax, $P$. ovale, $P$. malariae, \& P. knowlesi. P. falciparum is the most risky disease; as patients may progress to life-threatening illness within hours. Nonfalciparum species cause febrile illness but are rarely fatal, although deaths were reported with $P$. vivax and $P$. knowlesi infections (Saleh et al, 2019).

Menegon et al. (2018) reported that the histidine-rich protein 2 of $P$. falciparum is the most common malaria antigen targeted by rapid diagnostic tests for the specific diagnosis of $P$. falciparum. They added that pfhrp2 gene deletions were documented in the $P$. falciparum isolates from South America and some multiple endemic countries in Africa and Asia, which can produce false negative diagnostic results using HRP2based rapid diagnostic kits. They continued that the prevalence of $P$. falciparum parasites lacking pfhrp2, pfhrp3, which produces a second $P$. falciparum antigen that is recognized by PfHRP2 -based rapid diagnostic tests, and their flanking genes was evaluated in $135 P$. falciparum isolates from Gash Barka region and in 9 from Debug region, in Eritrea. By analysis, 56\% (81/144) of isolates were the pfhrp2/pfhrp3 positive; while $9.7 \%(14 / 144)$ showed deletion of the exon 2 of pfhrp2 gene and $43 \%(62 / 144)$ of isolates lacked the pfhrp3 gene. They concluded that pfhrp2 \& pfhrp3 deletion made the HRP2/3 based rapid diagnostic tests not so 
reliable for malaria in Eritrea.

Mukhtar et al. (2018) in South Sudan in 2009 launched a campaign for malaria control, using the Long Lasting Insecticide Nets (LLINs). The campaign success depended upon adequate available resources and reliable surveillance data helped officials understand existing infections. An optimal allocation of resources for malaria control at a sub-national scale is therefore paramount to the success of efforts to reduce malaria prevalence. They extended an existing SIR mathematical model to capture the effect of LLINs on malaria transmission. Available data on malaria is utilized to determine realistic parameter values of this model using a Bayesian approach via Markov Chain Monte Carlo (MCMC) methods. They explored the parasite prevalence on a continued rollout of LLINs in three different settings to create a sub-national projection of malaria and calculated the model's basic reproductive number and study its sensitivity to LLINs' coverage and its efficacy. They concluded that an effective use of LLINs might reduce malaria transmission, and recommended a scaling-up of the entry point of LLINs' distribution that targets households in areas at risk of malaria. Mukhtar et al. (2019) reported that malaria in South Sudan is endemic as one of the most severe diseases in the war-torn nation. The transmission severity might depend upon climatic conditions related to the reproduction of sporozoites attaching to female Anopheles saliva, especially in high altitude areas. The country experiences two different climatic conditions; namely one tropical and the other hot and semi-arid. They assessed the potential impact of climatic conditions on malaria prevalence in these two climatically distinct regions of South Sudan. They analyzed a host-mosquito disease-based model that includes temperature and rainfall. The model has also been parameterized in a Bayesian framework by using Bayesian Markov Chain Monte Carlo (MCMC). The mathematical analysis for this study has included equilibria, stability and a sensitivity index on the basic reproduction number $\mathrm{R} 0$. The threshold $\mathrm{R} 0$ is also used to provide a numerical basis for further refinement and prediction of the impact of climate variability on malaria transmission intensity over the study region. They highlighted the impact of various temperature values on the population dynamics of mosquito-vector.

As to mosquito-vector, the malaria parasite spreads among humans by female mosquitoes of the genus Anopheles (Diptera: $\mathrm{Cu}$ licidae), of about 400 different Anopheles species, only 30 were vectors of major importance (WHO, 2013). There are about 3.2 billion people at risk of contracting malaria; the greatest proportion of the total at risk population lives in Asia, malaria has the greatest health impact in Africa, which accounts for $80 \%$ of worldwide cases and $89 \%$ of deaths (WHO, 2014).

Malaria is one of the public health problems in Gedarif State, eastern Sudan, exists in hypo-meso-endemic zone of malaria (parasite prevalence 10.2 according to malaria prevalence and coverage indicator survey (FMOH, 2012). The main groups of malaria vectors in Africa are Anopheles gambiae, An. funestus, An. nili and An. vmoucheti (Harbach, 2004). Each of which comprises a complex or group of genetically distinct species of similar morphology, but vary in traits that affect their capacity in malaria transmission (Harbach, 2014). The highest risky of them is the An. gambiae complex, which comprises eight closely-related species that are distributed through sub-Saharan Africa (SSA), and its outer islands (Hunt et $a l, 1998)$. In the sub-Saharan Africa $90 \%$ of the world's malaria cases occurred (Gilles and Coetzee, 1987).

Eleven species of Anopheles were found in the Sudan, viz. An. arabiensis, An. gambiae, An. funestus, An. nili, An. dthali, An. squamosus, An. rufipes, An. pharoensis, An. pretor iensis, An. coustani, and An. multicolor (Nugud et al, 1997). White and Muniss (1972) in Sudan stated that An. pharoensis was $0.5 \%$ of total mosquito's population, and 
widely distributed in the eastern neighbor Ethiopia and eastern neighbor Somalia; it could also extend into Egypt in the north. Zahar (1974) reported that An. funestus, An. nili, An. pharoensis, An. rufipes and An. dthali were the commonest in Sudan with mild role in malaria transmission. An. gambiae Giles, An. arabiensis Patton of An. gambiae complex and An. funestus Giles from $A n$. funestus group were the most efficient vectors of malaria (Coetzee et al, 2000). An. arabiensis is the primary malaria vector throughout much of Sudan (Abuelmaali et $a l, 2013)$. Other species, such as An. funestus, An. nili, An. pharoensis, An. rufipes and An. dthali were reported in Sudan (Musa et $a l, 2012)$, but they play a negligible role in transmission. Transmitted by An. arabiensis, continues to be a major health problem in Sudan (Noor et al, 2012). Mosquitoes in Sudan eastern region were An. gambiae, An. funestus, An. rupicolus, An. pretoriensis, An. dthali, Culex nebulosus, C. sitiens, C. duttoni, C. univittatus, C. sinaiticus, C. laticinctus, C. fatigans (quinquefasciatus), C. poicilipes, C. simpsoni, C. pipiens, Aedes aegypti, Ae. caspius, Ae. metallicus, Ae. vittatus, Ae. arabiensis \& Ae. fowleri (El-Rayah, 2007).

Coetzee et al. (2000) reported that An. arabiensis belongs to An. gambiae species complex is one of the risky vectors or dominant malaria vector species in Sub-Saharan Africa and surrounding islands with a wide distribution including arid and urban areas. Seufi and Galal (2010) in White Nile State reported that An. arabiensis was the commonest species (80.7\%) Fuller et al. (2012) reported that An. arabiensis is the zoophilic, exophagic, and exophilic species, with a wide range of feeding and resting patterns, depending on geographical location to adapt quickly to counter indoor residual spraying control showing behavioral avoidance of sprayed surfaces depending on the type of insecticide used. They provided evidence of how land change and the species distribution models may be linked to project potential changes in vector habitat distribution and invasion potential. While gaps between potential habitat patches remained large in the Green Nile scenario, the models reveal large areas of future habitat connectivity that may facilitate the re-invasion of An. arabiensis from the Sudan into Upper Egypt. This species, by contrast, exhibits the greater behavioral plasticity, is more associated with outdoor habitats, and is more likely to bite susceptible persons out-doors (exophagy) as protections are less likely to be in place. Particularly, An. arabiensis is the well- known to favor dry (savannah) disturbed habitats while the larval habitats are primarily small, temporary, freshwater pools and other built features of the landscape, such as the rice fields and fish ponds (Sinka et al, 2010). Drake and Beier (2014) reported that the ecological niche modelling showed that $A n$. arabiensis is a climate generalist in the sense that it can occur in most of the African contemporary environmental range, and under three climate change scena- rios, its future distribution would expected to be reduced by $48 \%-61 \%$

As to the HIV, HIV-infected individuals have an increased propensity to develop malignancy (Engels et al, 2006). The spectrum of neoplasia in these patients is changing, especially in developed portions of the world, where the widespread use of highly active antiretroviral therapy (HAART) has limited the immunosuppression associated with HIV for prolonged periods in most patients (Spano et al, 2008). Holt et al. (2003) in the Dimma Refugee settlement in south-western Ethiopia investigated knowledge, attitudes and behaviors and HIV/STI prevalence of Sudanese refugees and Ethiopian sex workers in 1992. They found that in the early 1990s, knowledge about AIDS and condom use was low among Sudanese refugee women and none reported having ever used a condom. Also, sexual contact between refugee men and sex workers was frequent during this study time and the HIV prevalence and other STIs was high. They confirmed a widely held assumption that highly mobile 
and transient populations in Africa are susceptible to STIs and HIV, in large part due to their knowledge, attitudes and behaviors. Hewitt et al. (2006) reported that HIV and malaria infections often coexist in patients in many parts of the world due to geographic overlap of these two diseases, particularly true in sub-Saharan Africa, where an estimated 40 million people are living with HIV and more than 350 million episodes of malaria occur yearly. They added that there was evidence of a negative interaction between these two infections as HIV increased the risk of malaria infection and the development of clinical malaria, conversely, malaria increased HIV replication.

Jervase (2011) in 2009, estimated HIV prevalence in antenatal clinics across the 10 states that now make up South Sudan was $3.0 \%$, from zero in Northern Bahr el Ghazal to $7.2 \%$ in Western Equatoria State (WES). A review of HIV programmatic data in February 2012 suggested consistently higher HIV prevalence in WES than in other states. Because of concerns about the high HIV prevalence and the threat of a worsening epidemic among post-conflict communities, the South Sudan Ministry of Health requested assistance from CDC to investigate the high HIV prevalence in WES and provide recommendations for the public health response.

Rai et al. (2012) reported that the Republic of South Sudan faces a daunting task to improve public health and primary care in one of the poorest countries in the world. Very high maternal and child mortality rates must be a major concern for the new national government and for the many international agencies working in the country. Poor maternal health outcomes are primarily due to poor prenatal, delivery and post natal care services in health facilities, coupled with low literacy, widespread poverty, and poor nutrition among general population. Child mortality resulted of widespread malnutrition, pneumonia, malaria, vaccine preventable diseases and diarrheal diseases. National responses to HIV \& AIDS with international assistance have been encouraging with relatively low rates of infection. This paper explores barriers and identifies opportunities available to work toward achieving the targets for Millennium Development Goals (MDGs) $5 \& 4$ to reduce the maternal mortality from the current rate of 2,054 dea-ths per 100,000 live births, and child mortality (currently 135 deaths per 1,000 live births) respectively in the new nation. National and international organizations have a social responsibility to mobilize efforts to focus on maternal, child health and nutrition issues targeting the worst affected regions for improving access to primary care and obstetrical services. Initiatives are needed to build up community access to primary care with a well supervised community health workers program, as well as training mid-level management capacity with higher levels of funding from national and international sources to promote public health than current in the new republic.

CDC (2012) reported that HIV prevalence from antenatal clinics and voluntary counseling and testing (VCT) clinics in Western Equatoria State (WES) was higher than in other states $(10.7 \%$ among antenatal clinics with $95 \%$ CI of $8.0-14.2 \%$; $13.1 \%$ among VCT clinics with $95 \%$ CI of 10.0-17.0).

Baba et al. (2013) stated that data were limited on the human immunodeficiency virus (HIV) epidemic in South Sudan, which became an independent country on July 9, 2011, after decades of civil war. In 2009, estimated HIV prevalence in antenatal clinics across the ten states that now make up South Sudan was 3.0\%, ranging from zero in Northern Bahr el Ghazal to $7.2 \%$ in Western Equatoria State (WES). A review of the HIV programmatic data in February 2012 suggested consistently higher HIV prevalence in WES than in other states. Because of concerns about the high HIV prevalence and the threat of a worsening epidemic among postconflict communities, the Ministry of Health requested assistance from $\mathrm{CDC}$ to investi- 
gate the high HIV prevalence in WES and provided recommendations for the public health response. They reported that the HIV testing procedures were determined to be in accordance with the standard two-test serial testing algorithm used in South Sudan, and test results were accurately interpreted at the sites visited. Examination of records, review of commodity storage procedures, and crossmatching of results from confirmatory laboratories raised no substantial concerns about testing and laboratory practices. Among 420 first-visit the antenatal clinic attendees, HIV seropositivity was $10.7 \%$ (95\% confidence interval $[\mathrm{CI}]=8.0$ to $14.2 \%$ ), and among 388 voluntary counseling and testing attendees, HIV seropositivity was $13.1 \%$ (CI = 10.0 to $17.0 \%$ ), indicating high HIV prevalence in WES. Only $8.5 \%(\mathrm{CI}=6.0$ to $11.9 \%$ ) of voluntary counseling and testing attendees reported condom use at last sexual intercourse, with condom unavailability stated as a key barrier. The investigation also revealed a shortage of health-care workers and lack of supportive supervision in the facilities visited, limited HIV prevention services and access to HIV testing, and limited HIV care and treatment services.

Courtney et al. (2017) stated that after two decades of civil war, South Sudan has limited published data on HIV prevalence and behavioral determinants of HIV infection risk. A surge in HIV/AIDS prevalence is a real concern for this new country with limited access to medical or HIV preventive services, and low education and literacy levels. They presented findings from the first bio-behavioral surveillance survey conducted within the Sudan People's Liberation Army (SPLA).The sample included 1,063 survey participants (96.7\% male). Education levels within the SPLA are low; only $16.4 \%$ attended school beyond the primary level. The overall HIV prevalence in the sample was $5.0 \%$ (95\% confidence interval [CI]: 3.6-6.9). High-risk behaviors (e.g., multiple or concurrent sexual partners, heavy alcohol use, low condom use) were noted among
SPLA members. High levels of HIV stigma were identified: $90.6 \%(n=916)$ responded with one or more negative beliefs towards PLHIV, and $60.3 \%$ thought to be a healthylooking person with HIV should not be allowed to remain in the SPLA. They concluded that this first evaluation of risk behaviors and HIV prevalence among the SPLA highlight high-risk behaviors that may contribute to the spread of HIV. Understanding potential comorbid conditions will be critical to designing strategies to reduce HIV risk. This survey represented the first steps in understanding the HIV epidemic within SPLA.

Lodiongo et al. (2018) suggested that SD Bioline HIV/Syphilis Duo Assay was suitable for HIV \& syphilis testing in women attending antenatal services across South Sudan. Women with positive syphilis results should receive treatment immediately, but HIV positive women should undergo confirmatory testing following national HIV testing guidelines. Johnson et al. (2018) conducted a retrospective review of lab-confirmed HIV patients at Juba Teaching Hospital (JTH) from 2013 to 2016. They found 401 patients, with mean age $33.71 \pm 4.54$ years, $235(59 \%)$ were female, $307(77 \%)$ were late entry, $64(16 \%)$ were lost to follow-up, as $57(14 \%)$ died within a year of diagnosis. Among the patients who presented late, 122 (57\%) were female, \& 112 (53\%) were <34 years old. Among died patients $33(58 \%)$ were males with $52(91 \%)$ had CD4 counts $<350$ cells $/ \mathrm{mm}^{3}$ and WHO stage $>2$. They concluded that HIV late diagnosis was a significant public health problem, particularly in younger and female patients. Bobbio et al. (2019) in South Sudan correlated between HIV and TB evaluated diagnostic method to detect extra-pulmonary in extremely resource-limited settings, with visceral leishmaniasis in differential diagnosis with overlapping sonographic feature. They focused assessment with sonography for HIV-and TB was a relevant diagnosis to detect TB signs. WHO (2018) stated that HIV continues to be a major global public health issue, having 
claimed more than 35 million lives so far. In 2017, 940000 people died from HIV-related causes globally

\section{Conclusion}

Malaria (in the presence of aggressive vector An. arabiensis) and HIV are risky infectious diseases that desire more national collaborative studies especially in co-infection.

\section{References}

Abuelmaali, SA, Elaagip, AH, Basheer, MA, Frah, EA, Ahmed, FT, et al, 2013: Impacts of agricultural practices on insecticide resistance in the malaria vector Anopheles arabiensis in Khartoum State, Sudan 8:e80549.

Baba, SP, Jervase, A, Dokubo, KE, Clarke, K, 2013: Investigation of High HIV Prevalence in Western Equatoria State-South Sudan, 2012: MMWR Morb Mortal Wkly Rep. 62, 22: 453-4.

Best, $\mathbf{C}$, Neufingerl, $\mathbf{N}$, van Geel, L, van den Briel, T, Osendarp, S, 2010: The nutritional status of school-aged children: why should we care? Food Nutr. Bull. 31, 3:400-17.

Bobbio, F, Di Gennaro, F, Marotta, C, Kok, J, Akec, G, et al, 2019: Focused ultrasound to diag-nose HIV-associated tuberculosis (FASH) in the extremely resource-limited setting of South Sudan: A cross-sectional study. BMJ Open 9, 4:e027179.

CDC, 2012: Notes from the field: Investigation of high HIV prevalence in Western Equatoria State-South Sudan, MMWR Morb. Mortal Wkly. Rep. 2013. June 7, 62, 22:453-4.

Charchuk, R, Houston, S, Hawkes, MT, 2015: Elevated prevalence of malnutrition and malaria among school-aged children and adolescents in war-ravaged South Sudan. Pathog. Glob. Hlth. 109, 8: 395-400.

Drake, JM, Beier, JC, 2014: Ecological niche and potential distribution of Anopheles arabiensis in Africa in 2050. Malar J. 13:213. is in Africa in 2050. Malar J. 13:213. doi: 10.

Coetzee, M, Craig, M, Le Sueur, D, 2000: Distribution of African malaria mosquitoes belonging to the Anopheles gambiae complex. Parasitol. Today 16:74-7.

Courtney, LP, Goco, N, Woja, J, Farris, T, Cummiskey, C, Smith, E, et al, 2017: HIV prevalence and behavioral risk factors in the Sudan People's Liberation Army: Data from South Sudan. PLoS One Nov 21;12(11):e0187689.doi:

10.1371/journal.pone.0187689.eCollection 2017.

Deen, JL, Walraven, GE, von Seidlein, L,
2002: Increased risk for malaria in chronically malnourished children under 5 years of age in rural Gambia. J. Trop. Pediatr. 48, 2:78-83.

Deribew, A, Alemseged, F, Tessema, F, Sena, L, Birhanu, Z, et al, 2010: Malaria and undernutrition: A community based study among under-five children at risk of malaria, south-west Ethiopia. PLoS ONE 5(5):e10775.10.1371/jour nal. pone. 0010775

El-Rayah, EM, 2007: Mosquitoes of the Sudan. Sudan Notes \& Records 6:153-87.

Engels, EA, Pfeiffer, RM, Goedert, JJ, et al, 2006: Trends in cancer risk among people with AIDS in the United States 1980-2002. AIDS 20: 1645-50.

Fillol, F, Cournil, A, Boulanger, D, Cisse, B, Sokhna, C, Targett G, et al, 2009: Influence of wasting and stunting at the onset of the rainy season on subsequent malaria morbidity among rural preschool children in Senegal. Am. J. Trop. Med. Hyg. 80, 2:202-8.

FMOH, 2012: Malaria Indicators Survey, Federal Ministry of Health, Sudan.

Fuller, DO, Parenti, MS, Hassan, AN, Beier, JC, 2012: Linking land cover and species distribution models to project potential ranges of malaria vectors: an example using Anopheles arabiensis in Sudan and Upper Egypt. Malar. J. Aug 6;11:264. doi: 10.1186/1475-2875-11-264.

Gilles, MT, Coetzee, M, 1987: A Supplement to Anophelinae of Africa South of the Sahara: Publications of the South African Institute for Medical Research No. 55 Johannesburg.

Harbach, RE, 2004: The classification of genus Anopheles (Diptera: Culicidae): A working hypothesis of phylogenetic relationships. Bull. Entomol. Res. 94:537-53.

Harbach, RE, 2014: Mosquito taxonomic inventory. http://mosquito-taxonomicinventory. 2013 info/Accessed. 2014.

Hewitt, K, Steketee, R, Mwapasa, V, et al, 2006: Interactions between HIV and malaria in non-pregnant adults: evidence and implications. AIDS 20:1993-9.

Holt, BY, Effler, P, Brady, W, Friday, J, Belay, E, et al, 2003: Planning STI/HIV prevention among refugees and mobile populations: situateion assessment of Sudanese Refugees. Disasters 27, 1:1-15.

Hunt, RH, Coetzee, M, Fettene, M, 1998: The Anopheles gambiae complex: A new species from Ethiopia. Tran. R. Soc. Trop. Med. Hyg. 92:231-5. 
Jervase, A, 2011: HIV prevalence in South Sudan: Data from the ANC sentinel surveillance 2009. S. Sudan Med. J. 4:49-56.

Johnson, M, Lemi, BL, Tonny, HL, David, A D, Boru, W, et al, 2018: Late entry to HIV and AIDS care and treatment, Juba Teaching Hospital, Juba, South Sudan, 2013-2016. Afr. J. AIDS Res. 17, 2:213-6.

Lewnard, JA, Berrang-Ford, L, Lwasa, S, Namanya, DB, Patterson, KA, et al, 2014: Relative undernourishment and food insecurity associations with plasmodium falciparum among $\mathrm{Ba}-$ twa pygmies in Uganda: Evidence from a crosssectional survey. Am. J. Trop. Med. Hyg. 91, 1: 39-49.

Lodiongo, DK, Bior, BK, Dumo, GW, Katoro, JS, et al, 2018: Field evaluation of SD BIOLINE HIV/Syphilis Duo assay among pregnant women attending routine antenatal care in Juba, South Sudan. PLoS One Oct. 10;13(10):e020538 3. doi: 10.1371/journal.pone. 0205383.

Menegon, M, L'Episcopia, M, Nurahmed, A M, Talha, AA, Nour, BYM, et al, 2017: Identification of Plasmodium falciparum isolates lacking histidine-rich protein 2 and 3 in Eritrea. Infect. Genet. Evol. 55:131-4.

Mukhtar, AYA, Munyakazi, JB, Ouifki, R, 2019: Assessing the role of climate factors on malaria transmission dynamics in South Sudan. Math. Biosci. 310:13-23.

Mukhtar, AYA, Munyakazi, JB, Ouifki, R, Clark, AE, 2018: Modelling the effect of bednet cover-age on malaria transmission in South Sudan. PLoS One Jun 7, 13(6):e0198280. doi: 10. 1371/ journal.pone.0198280.

Murray, MJ, Murray, AB, Murray, MB, Murray, CJ, 1976: Somali food shelters in the Ogaden famine and their impact on health. Lancet 307, 7972:1283-5.

Musa, MI, Shohaimi, S, Hashim, NR, Krishnarajah, I, 2012: A climate distribution model of malaria transmission in Sudan. Geospatial Hlth. 7:27-36.

Nguyen, C, 2016: Malaria ravages South Sudan. http://www.healthmap.org/site/diseas.edaily/article/malaria-ravages-south-sudan.11016.

Noor, AM, EIMardi, KA, Abdelgader, TM, Patil, AP, Amine, AA, et al, 2012: Malaria Risk Mapping for Control in the Republic of Sudan. Am. J. Trop. Med. Hyg. 87:1012-21.

Nugud, AD, Eltayeb, RA, Abd-Elnur, OM,
1997: Vectors of Malaria in Sudan. Unpublished paper joint workshop on scientific cooperation: The Federal Ministry of Agriculture and Forestry; Sudan and ICIPE, Kenya, Khartoum, Sudan.

Ortu, G, Khan, J, Samuel, Yibi, M, Abdu Nimaya, I, 2017: Mass drug administration in central Equatoria, South Sudan: results \& suggestions for future distributions. Int. Hlth. 9, 4:263-6.

Pasquale, H, Jarvese, M, Julla, A, Doggale, C, Sebit, B, et al, 2013: Malaria control in South Sudan, 2006-2013: strategies, progress and challenges. Malar. J. Oct 27, 12:374. doi: 10.1186/ 1475-2875-12-374.

Rai, RK, Ramadhan, AA, Tulchinsky, TH, 2012: Prioritizing maternal and child health in independent South Sudan. Matern Child Hlth. J. 16, 6:1139-42.

Saleh, AMA, El Nakib, MM, Malek, DMA, Morsy, TA, 2019: Mini-review on malaria and human immunodeficiency virus in Sub-Sahara Africa. J. Egypt. Soc. Parasitol.. 49, 1:61-72

Seufi, AM, Galal, FH, 2010: Role of Culex and Anopheles mosquito species as potential vectors of rift valley fever virus in Sudan outbreak, 2007. BMC Infect. Dis. 10:65. doi:10.1186/ 1471-2334-10-65.

Sinka, ME, Bangs, MJ, Manguin, S, Coetzee, M, Mbogo, CM, et al, 2010: The dominant $\mathrm{An}$ opheles vectors of human malaria in Africa, Europe and the Middle East: occurrence data, distribution maps and bionomic précis. Parasit. Vectors 3:117. doi: 10.1186/1756-3305-3-117.

Spano, JP, Costagliola, D, Katlama, C, et al, 2008: AIDS-related malignancies: State of the art and therapeutic challenges. J. Clin. Oncol. 26:4834-8.

White, GB, Muniss, JN, 1972: Taxonomic value of spermatheca size for distinguishing between four members of the Anopheles gambiae complex of mosquitoes in East Africa. Bull. WHO 46:793-9.

WHO, 2013: Malaria entomology and vector control: Guide for Participants. Geneva, Switzerland.

WHO, 2014: Malaria Vector Control Commodities Landscape, $2^{\text {nd }}$ Edn. CH-1211 Geneva 27, Switzerland.

WHO, 2018: Fact sheets HIV/AIDS World day. Zahar, A, 1974: Review of the ecology of malaria vectors in the WHO Eastern Mediterranean Region. Bull. WHO 50:427-40. 